\title{
A Study on Load Carrying Capacity of Fly Ash Based Polymer Concrete Columns Strengthened Using Double Layer GFRP Wrapping
}

\author{
S. Nagan $^{1}$ and S. Karthiyaini ${ }^{2}$ \\ ${ }^{1}$ Department of Civil Engineering, Thiagarajar College of Engineering, Thiruparankundram, Madurai, Tamil Nadu 625015, India \\ ${ }^{2}$ Department of Civil Engineering, Latha Mathavan Engineering College, Madurai, Tamil Nadu 630561, India \\ Correspondence should be addressed to S. Karthiyaini; karthiyaini.s@gmail.com
}

Received 31 March 2014; Revised 11 September 2014; Accepted 14 September 2014; Published 12 November 2014

Academic Editor: Amit Bandyopadhyay

Copyright (C) 2014 S. Nagan and S. Karthiyaini. This is an open access article distributed under the Creative Commons Attribution License, which permits unrestricted use, distribution, and reproduction in any medium, provided the original work is properly cited.

\begin{abstract}
This paper investigates the suitability of glass fiber reinforced polymer (GFRP) sheets in strengthening of fly ash based polymer members under compression. Experimental results revealed that load carrying capacity of the confined columns increases with GFRP sheets wrapping. Altogether 18 specimens of M30 and G30 grade short columns were fabricated. The G30 specimens were prepared separately in 8 molarity and 12 molarity of sodium hydroxide concentration. Twelve specimens for low calcium fly ash based reinforced polymer concrete and six specimens of ordinary Portland cement reinforced concrete were cast. Three specimens from each molarity fly ash based reinforced polymer concrete and ordinary Portland cement reinforced concrete were wrapped with double layer of GFRP sheets. The load carrying capacity of fly ash based polymer concrete was tested and compared with control specimens. The results show increase in load carrying capacity and ductility index for all strengthened elements. The maximum increase in load carrying capacity was $68.53 \%$ and is observed in strengthened G30 specimens.
\end{abstract}

\section{Introduction}

Concrete is a versatile construction material and is being used worldwide. But the greenhouse gas $\left(\mathrm{CO}_{2}\right)$ produced during its manufacturing process causes environmental impact. Fly ash based polymer binders have emerged as the best possible alternatives for cement binders for applications in concrete industry reducing the environmental deterioration. Fly ash based polymer is synthesized by mixing aluminosilicatereactive material with strong alkali solutions, such as sodium hydroxide $(\mathrm{NaOH})$, potassium hydroxide $(\mathrm{KOH})$, sodium silicate, or potassium silicate [1]. However the development of this material is still in its nascent stage. These fly ash based polymer elements are reinforced with conventional type of reinforcement which are subjected to flexure and compression. Under heavy loading conditions, these elements experience cracks or failures. The strengthening and retrofitting of these elements is an innovative concept. In recent years, the use of externally bonded fiber-reinforced polymers (FRP) is popular in civil infrastructure applications including wrapping of concrete columns. Significant research has been devoted to circular columns retrofitted with FRP and numerous models were proposed. Shahawy et al. verified a confinement model which was originally developed for concrete filled glass FRP tubes. The original development was conducted by exerting axial compression tests on a total of over 45 carbon-wrapped concrete stubs of two batches of normal and high strength concrete and 5 different numbers of wraps. At the end of the development it was concluded that the wrap significantly enhanced the strength and ductility of concrete by curtailing its lateral dilation and the adhesive bond between concrete and the wrap would not significantly affect the confinement behavior [2]. Toutanji and Deng have performed tests to evaluate the durability performance of 
concrete columns confined with fiber-reinforced polymer composite sheets [3].

Fly ash based polymer binders have emerged as the best possible alternative to cement binders for applications in concrete industry. Fly ash based polymer is synthesized by mixing aluminosilicate-reactive material with strong alkali solutions, such as sodium hydroxide $(\mathrm{NaOH})$, potassium hydroxide ( $\mathrm{KOH})$, sodium silicate, or potassium silicate [4]. However the development of this material is still in its infancy and a number of research works were carried out in this field. These fly ash based polymer elements were reinforced with conventional type of reinforcement and these elements were subjected to flexure, compression, and so forth, where these elements crack or meet a point of failure, under heavy loading conditions. The strengthening and retrofitting of these elements is an innovative concept. In recent years, the use of externally bonded fiber-reinforced polymers (FRP) has become increasingly popular for civil infrastructure applications, including wrapping of concrete columns. Significant research has been devoted to circular columns retrofitted with FRP and numerous models were proposed. A confinement model was verified which was originally developed for concrete filled glass FRP tubes by conducting axial compression tests on a total of 45 carbonwrapped concrete stubs of two batches of normal and high strength concrete and five different numbers of wraps. It was concluded that the wrap significantly enhanced the strength and ductility of concrete by curtailing its lateral dilation and the adhesive bond between concrete and the wrap would not significantly affect the confinement behavior [5]. The influence of wet/dry exposure using salt water on the strength and ductility of FRP wrapped concrete columns was evaluated. It was observed that the confinement of concrete cylinders with FRP sheets substantially improves the compressive strength and ductility and the improvement in strength and ductility depends on the FRP composite sheets. The behavior of FRP wrapped concrete cylinders with different wrapping materials and bonding dimensions has been studied by Lau and Zhou using finite element (FEM) and analytical methods [6]. The confinement model describing the behavior of rectangular concrete columns retrofitted with the externally bonded fiber-reinforced polymer material and subjected to axial stress was undertaken by Chaallal et al. [7].

The technique of wrapping thin, flexible, high strength fiber composite straps around the columns for seismic strengthening to improve the confinement, thereby increasing the ductility and strength, was investigated by Saadatmanesh et al. [8]. The enhancement in axial load for RCC short columns was about $4.05 \%$ and $16.22 \%$, for one and two layers of GFRP, respectively, which shows that two layers of GFRP increase the load carrying capacity by four times compared to that of single layer wrapping [9]. Thus, FRP wrapping of circular columns has been proved to be an effective retrofitting technique. The aim of the paper is to present the behavior of reinforced fly ash based polymer circular columns strengthened by wrapping GFRP sheets externally and subject it to axial compressive loading.

\section{Fly Ash Based Polymer Concrete Short Column}

The use of externally bonded GFRP composite for strengthening and repairing can be a cost-effective alternative for restoring or upgrading the performance of existing fly ash based polymer short columns. The objective of the research was to determine the failure and to examine the effects of external confinement on the strength performance of fly ash based polymer short columns. The fly ash based polymer concrete circular short column was cast and loaded axially to determine the compressive strength, and then the column was wrapped by two layers of GFRP in scattered directions and subjected to axial compressive loading.

\subsection{Materials}

2.1.1. Fly Ash. In the present study, the low calcium fly ash (ASTM Class F) was used as the aluminosilicate source material for making fly ash based polymer binder. The specific gravity of the fly ash used in the study was 1.9, and $90 \%$ of the fly ash passed through the $45 \mu \mathrm{m}$ sieve. The chemical composition of the fly ash as determined by X-ray fluorescence analysis is presented in Table 1.

2.1.2. Alkali. The alkali used consisted of a mixture of $\mathrm{NaOH}$ and $\mathrm{Na}_{2} \mathrm{SiO}_{3}$ solution. $\mathrm{NaOH}$ flakes in the tune of $98 \%$ purity were used to make the $\mathrm{NaOH}$ solution of desired molarity. In this investigation, sodium hydroxide concentrations of $8 \mathrm{M}$ and $12 \mathrm{M}$ were used to manufacture various specimens. 320 grams of sodium hydroxide in flake form was dissolved in 1 litre of potable water to make $8 \mathrm{M}$ solution. 480 grams of sodium hydroxide in flake form is dissolved in 1 litre of potable water to make $12 \mathrm{M}$ solution [10].

2.1.3. Aggregates. Crushed granite rock and natural river sand were used as coarse and fine aggregates, respectively. The nominal sizes of coarse and fine aggregates were 20 and $4.75 \mathrm{~mm}$. The specific gravity of coarse and fine aggregates was 2.72 and 2.64 , respectively. The fine aggregate had a fineness modulus of 2.36 .

2.2. Mixing, Casting, and Curing. Ordinary Portland cement of grade 53 was used to prepare the M30 grade. The design mix ratio for M30 grade concrete is $1: 1.47: 2.4$ with water/cement ratio of 0.40 . Pan mixer was used to mix the concrete and an effective control on water/cement ratio was maintained to achieve good results [11]. The materials for fly ash based polymer concrete were mixed as per details provided in Table 2.

Addition of $\mathrm{NaOH}$ and sodium silicate solution leads to high temperatures and, moreover, different investigators propose various mixing proportions of alkali solution. For the present study, the alkali solution was first prepared by thoroughly mixing the $\mathrm{NaOH}$ and $\mathrm{Na}_{2} \mathrm{SiO}_{3}$ solution. The solution was prepared 24 hours prior to its use to bring down its temperature to the ambient temperature. Coarse and fine 
TABLE 1: Chemical composition of fly ash.

\begin{tabular}{lcc}
\hline S. number & Parameter & Content (\% by mass) \\
\hline 1 & $\mathrm{SiO}_{2}$ & 59.7 \\
2 & $\mathrm{Al}_{2} \mathrm{O}_{3}$ & 28.36 \\
3 & $\mathrm{Fe}_{2} \mathrm{O}_{3}+\mathrm{Fe}_{2} \mathrm{O}_{4}$ & 4.57 \\
4 & $\mathrm{CaO}$ & 2.1 \\
5 & $\mathrm{Na}$ & 0.04 \\
6 & $\mathrm{MgO}$ & 0.83 \\
7 & $\mathrm{Mn}_{2} \mathrm{O}_{3}$ & 0.04 \\
8 & $\mathrm{TiO}_{2}$ & 1.82 \\
9 & $\mathrm{SO}_{3}$ & 0.4 \\
10 & $\mathrm{Others}_{1}$ & 2.14 \\
11 & Loss of ignition & 1.06 \\
\hline
\end{tabular}

TABLE 2: Mixture proportions of G30 (quantity in $\mathrm{kg}$ per $\mathrm{m}^{3}$ of concrete mix)

\begin{tabular}{lcc}
\hline S. number & Constituent materials & G30 \\
\hline 1 & Coarse aggregate $(6 \mathrm{~mm})$ & 363 \\
2 & Coarse aggregate $(12 \mathrm{~mm})$ & 543 \\
3 & River sand & 554 \\
4 & Fly ash & 378 \\
5 & Sodium hydroxide & 50 \\
6 & Sodium silicate & 124 \\
7 & Super plasticizer & 8 \\
\hline
\end{tabular}

aggregates in saturated dry condition were well mixed with fly ash in a $150 \mathrm{~kg}$ pan mixture.

To improve the workability of concrete, high range water reducing polycarboxylic based super plasticizer was added to the mixture. In the present study, GLENIUM B233 was used. The fresh concrete was poured into the column mould and cube mould of $150 \mathrm{~mm} \times 150 \mathrm{~mm} \times 150 \mathrm{~mm}$ in three layers. For better and uniform compaction, each layer was vibrated for 2 minutes on a table vibrator. Slump cone test was done to find out the workability of fresh concrete. The specimens having $190 \mathrm{~mm}$ diameter and height of $800 \mathrm{~mm}$ were cast using standard steel moulds. Concrete specimens were compacted with the help of a table vibrator. Tops of the moulds were covered with steel plates and edges were sealed immediately after casting to avoid loss of water from the specimen.

Heat curing was adopted for this study, because this curing substantially assisted the chemical reaction that occurred in the fly ash based polymer concrete. It was done by two methods, namely, steam curing and dry curing. The compressive strength of dry-cured fly ash based polymer concrete is approximately $15 \%$ greater than that of steamcured fly ash based polymer concrete [12]. The curing method adopted for this study was dry-heat curing. Rectangular steel chamber with thermostats was exclusively designed for this research work. It was designed in such a way that the temperature inside the chamber could be adjusted between $60^{\circ} \mathrm{C}$ and $90^{\circ} \mathrm{C}[13]$.
2.3. Testing of Specimen. A total of four Fly ash based polymer concrete circular columns with reinforcement were cast. Fly ash based polymer concrete columns were wrapped using GFRP sheets by two layers. The short columns were tested in a ACCRO-Tech AT-118 compression testing machine of capacity $2000 \mathrm{kN}$. The specimens were tested under monotonically increasing axial compression. Observed cracks were also monitored and marked. The short columns of outer diameter $190 \mathrm{~mm}$ and inner diameter $100 \mathrm{~mm}$ with overall length of $800 \mathrm{~mm}$ were cast. The longitudinal reinforcement ratio is kept constant as $2.89 \%$ for all the specimens. Table 4 gives the details of specimens cast along with reinforcement provided. The test specimens were grouped into two different mixes, taking the mix of concrete as variable. Columns were reinforced with four $12 \mathrm{~mm}$ deformed bars as longitudinal reinforcement and $8 \mathrm{~mm}$ bars @ $100 \mathrm{~mm}$ spacing as lateral reinforcement. To avoid the crushing of ends due to concentration of load, $8 \mathrm{~mm}$ bars @ $25 \mathrm{~mm} \mathrm{c} / \mathrm{c}$ were provided for a length of $100 \mathrm{~mm}$ on either end of column. The reinforcement details are illustrated in Figure 1.

The specimen names, as shown in Table 3, were composed of three terms. Each of these terms gives information about some aspect of the column which is described as follows. The first term refers to the control specimen (CS) for M30 grade of ordinary reinforced concrete column with and without wrapping. The second term refers to the reinforced fly ash based polymer concrete column (RGCC) for G30 grade of concrete. The third term refers to the strengthening of reinforced fly ash based polymer concrete column (RGCCS) for G30 grade of concrete strengthened using GFRP sheets.

2.4. Glass Fiber-Reinforced Polymer Wrapping. The resin system used in this study was made of two parts, namely, resin and hardener. The components were mixed manually for 5 minutes. The concrete columns were cleaned and completely dried before the resin was applied. A first coat of thin layer of resin was applied and GFRP sheet was then wrapped directly on the surface. Special attention was taken to ensure that there was no void between the GFRP sheet and the concrete surface. After the first wrap of the GFRP sheet application, a second layer of resin was applied on the surface of the first layer to allow the impregnation of the second layer of the GFRP sheet. Finally, a layer of resin was applied on the surface of wrapped columns. In all cases, the outside layer was extended by an overlap of $50 \mathrm{~mm}$ to ensure the development of full composite strength.

2.5. Resin. The resin system used in this work was general purpose polyester resin made of two parts, resin and hardener. The manufacturer provided the following information on E-glass composite (resin + fiber) laminates that were used to wrap concrete columns: ultimate tensile strength $=$ $250 \mathrm{~N} / \mathrm{mm}^{2}$, modulus of elasticity $=10500 \mathrm{~N} / \mathrm{mm}^{2}$, and ultimate strain $=3.5 \%$ maximum.

2.6. Instrumentation and Testing Procedure. All specimens were tested in a compression testing machine of capacity $2000 \mathrm{kN}$. The specimens were loaded into the testing frame 
TABLE 3: Details of test specimens.

\begin{tabular}{lcccc}
\hline S. number & Specimen details & Grade of concrete & Molarity & Strengthening material used \\
\hline 1 & CS11 & M30 & - & - \\
2 & CS12 & M30 & - & - \\
3 & RGCC[8]-1 & G30 & 12 & - \\
4 & RGCC[12]-1 & G30 & 8 & GFRP \\
5 & RGCCS[8]-1 & G30 & GFRP \\
6 & RGCCS[12]-1 & G30 & 12 & GFRP \\
\hline
\end{tabular}

TABLE 4: Details of columns and their results.

\begin{tabular}{|c|c|c|c|c|c|c|}
\hline S. number & $\begin{array}{l}\text { Specimen } \\
\text { details }\end{array}$ & $\begin{array}{l}\text { Failure loads in } \\
\text { kN }\end{array}$ & $\begin{array}{l}\text { Calculated load } \\
\text { in } \mathrm{kN}\end{array}$ & $\begin{array}{c}\text { Correlation } \\
\text { ratio }\end{array}$ & $\begin{array}{l}\text { Comp. strength } \\
\text { of column } \\
(\mathrm{MPa})\end{array}$ & Ductility Index \\
\hline 1 & CS11 & 413 & 307.85 & 1.34 & 28.98 & 0.95 \\
\hline 2 & CS12 & 491 & 307.85 & 1.59 & 32.22 & 1.02 \\
\hline 3 & RGCC $[8]-1$ & 544 & 307.85 & 1.76 & 34.86 & 0.94 \\
\hline 4 & RGCC[12]-1 & 546 & 307.85 & 1.77 & 38.88 & 1.08 \\
\hline 5 & RGCCS[8]-1 & 862 & 307.85 & 2.8 & 46.44 & 1.26 \\
\hline 6 & RGCCS[12]-1 & 866 & 307.85 & 2.81 & 48.84 & 1.36 \\
\hline
\end{tabular}

until failure point and exerted under axial compression. All the columns were tested under similar conditions. This test setup is shown in Figure 2.

\section{Results and Discussion}

3.1. Overall Behavior. The maximum experimental values obtained from all the tests are summarized in Table 4 and Figure 3. From the results, it is observed that the reinforced fly ash based polymer concrete columns with GFRP wrap increase the load carrying capacity when compared to the ordinary reinforced concrete columns. The compressive strength of the CS12, RGCC[8]-1, RGCC[12]-1, RGCCS[8]1 , and RGCCS[12]-1 increases by $11.18 \%, 20.28 \%, 34.16 \%$, $60.24 \%$, and $68.53 \%$, respectively, when compared with CS11. The load carrying capacity and the longitudinal stiffness of GFRP wrapped columns increased while their ductility decreased with the increasing number of GFRP layers [14]. The above nonlinearity in compressive strength when increasing the number of fiber layers may be attributed to crushing of resin lying in between the fibers. When the resin started to crush, a sudden drop in substantial load transfer occurred and, as a result, nonlinearity in axial deformation control was observed [15].

3.2. Ductility Response. The concept of ductility is related to the ability to sustain inelastic deformations without substantial decrease in the load carrying capacity. It is well established that whenever the grade of concrete increases, the material tends to result in lower ductility. The members strengthened by using the high modulus FRP exhibited ductile response leading to very high deflections even after higher ultimate load was reached [16]. The Ductility Index $(\mu)$ of column was evaluated from the ratio of compressive strength of reinforced column to the compressive strength of plain concrete cube. From the results it is evident that confinement with GFRP wrap improved the column's ductility. This increased ductility allows a higher level of axial strain and a failure point corresponding to rupture of the GFRP wrapping. In most of the cases, failure began at or near a corner, because of the high stress concentrations at these locations. The ductility of the columns increased as the number of layers of wrapping increased. At the same stress level, the axial strains for the GFRP confined columns were always higher than the transverse strains.

3.3. Failure Mode. Failure of the control columns was notably more violent than the columns with GFRP and observed to be even explosive. Local buckling of longitudinal reinforcement was observed in the unwrapped columns. For most wrapped columns, the failure point was associated with concrete crushing at or near the column ends and marked by wraps rupturing in the circumferential direction. After the failure point, the concrete was found disintegrated. Failure of GFRP wraps was observed at or near a corner in all the specimens mainly due to stress concentrations. One should also ensure that the failure point will not happen at end regions by increasing the number of wrapping layers in the end regions [9]. The use of GFRP materials restores or improves the column original design strength for possible axial, shear, or flexure and, in some cases, allows the structure to carry more load than it was designed for. In most cases, the ductility of the columns has improved. With development of additional design standards and increased demand in the field applications, FRP will continue to grow in popularity as retrofit material [17].

Failure modes of specimens are shown in Figure 4. 

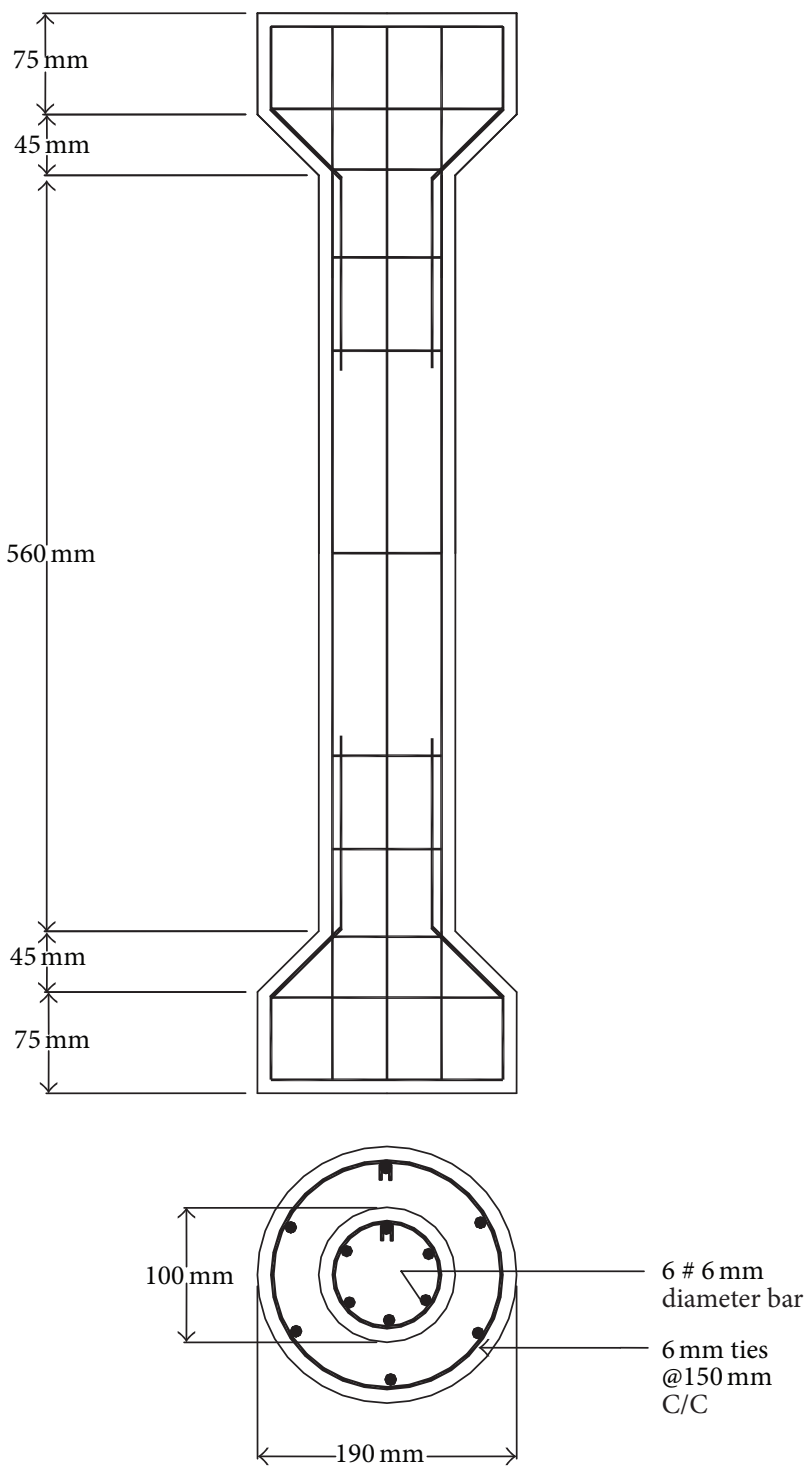

FIGURE 1: Reinforcement details.

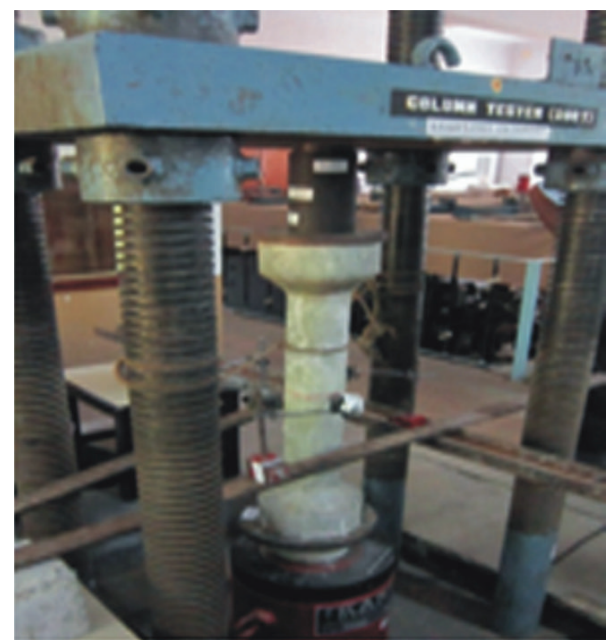

FIGURE 2: Experimental setup.

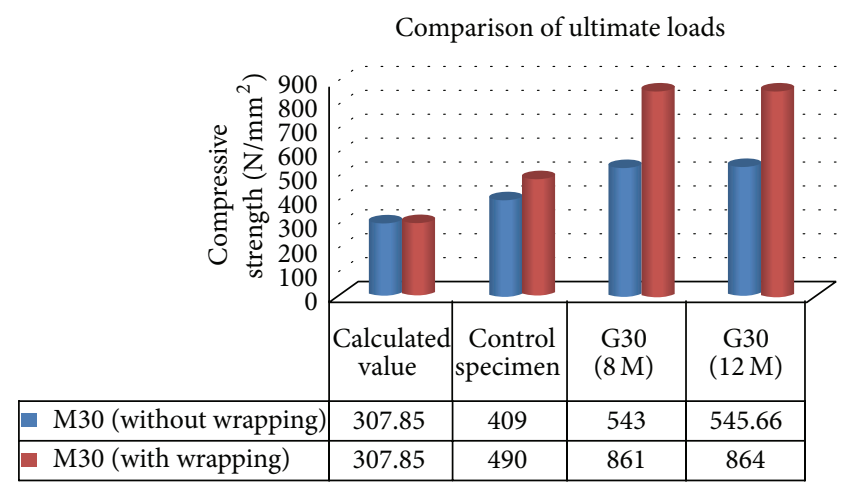

FIGURE 3: Comparisons of ultimate loads.
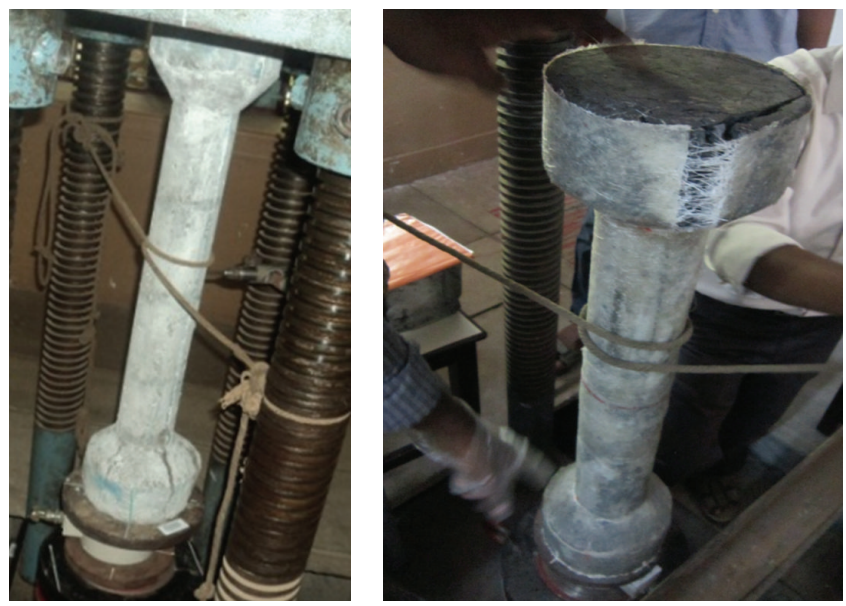

FIGURE 4: Failure crack pattern (before and after wrapping).

\section{Conclusions}

Based on the experimental tests conducted on fly ash based polymer concrete columns and ordinary concrete columns, it can be concluded that the bonding of fly ash based polymer paste and aggregates is very strong and cohesive. The ultimate load capacity of G30 grade fly ash based polymer concrete columns is much higher than the M30 grade of control columns and also exhibits weaker shear failure. Fly ash based polymer concrete columns show less deformation than that of control columns for same percentage of steel. Effective confinement with GFRP composite sheets resulted in improving the compressive strength. Better confinement was achieved when the number of layers of GFRP wrap was increased, resulting in enhanced load carrying capacity of the column, in addition to the improvement of the ductility. Use of GFRP in concrete compression members produces an increase in strength, but this phenomenon is strongly influenced by the aspect ratio of the cross section. The test results show a clear overall linear relationship between the strength of confined concrete and lateral confining pressure provided by GFRP. 


\section{Conflict of Interests}

The authors declare no conflict of interests.

\section{References}

[1] J. Davidovits, Fly Ash Based Polymer Chemistry and Application, Institute Fly Ash Based Polymer, Saint-Quentin, France, 2008.

[2] M. Shahawy, A. Mirmiran, and T. Beitelman, "Tests and modeling of carbon-wrapped concrete columns," Composites B: Engineering, vol. 31, no. 6-7, pp. 471-480, 2000.

[3] H. Toutanji and Y. Deng, "Strength and durability performance of concrete axially loaded members confined with AFRP composite sheets," Composites Part B: Engineering, vol. 33, no. 4, pp. 255-261, 2002.

[4] J. Davidovits, "Soft Mineralogy and Geopolymers," in Proceedings of the Fly ash Based Polymer 88 International Conference, the Université de Technologie, Compiègne, France, 1988.

[5] P. Taghia and S. A. Bakar, "Mechanical behaviour of confined reinforced concrete-CFRP short column- based on finite element analysis," World Applied Sciences Journal, vol. 24, no. 7, pp. 960-970, 2013.

[6] K. T. Lau and L. M. Zhou, "The mechanical behavior of composite-wrapped concrete column subjected to uni-axial compression load," Composite Structures, vol. 52, no. 2, pp. 189198, 2001.

[7] O. Chaallal, M. Hassan, and M. Shahawy, "Confinement model for axially loaded short rectangular columns strengthened with fiber-reinforced polymer wrapping," ACI Structural Journal, vol. 100, no. 2, pp. 215-221, 2003.

[8] H. Saadatmanesh, M. R. Ehsani, and M. W. Li, "Strength and ductility of concrete columns externally reinforced with fiber composite straps," ACI Structural Journal, vol. 91, no. 4, pp. 130139, 1994.

[9] R. Kumutha, R. Vaidyanathan, and M. S. Palanichamy, "Behaviour of reinforced concrete rectangular columns strengthened using GFRP," Cement and Concrete Composites, vol. 29, no. 8, pp. 609-615, 2007.

[10] D. Hardjito and B. V. Rangan, "Development and properties of low-calcium fly ash-based geopolymer concrete," Research Report GC-1, Faculty of Engineering, Curtin University of Technology, 2005.

[11] T. Sujatha, K. Kannapiran, and S. Nagan, "Strength assessment of heat cured geopolymer concrete slender column," Asian Journal of Civil Engineering, vol. 13, no. 5, pp. 635-646, 2012.

[12] D. Hardjito, S. E. Wallah, and B. V. Rangan, "Study on engineering properties of fly ash-based geopolymer concrete," Journal of the Australasian Ceramic Society, vol. 38, no. 1, pp. 44-47, 2002.

[13] K. Kannapiran, T. Sujatha, and S. Nagan, "Durability study on alumino-silicate concrete, synthesized using anthracite coal fly ash," Journal of Structural Engineering, vol. 38, no. 1, pp. 94-100, 2011.

[14] Z. Tao, L.-H. Han, and L.-L. Wang, "Compressive and flexural behaviour of CFRP-repaired concrete-filled steel tubes after exposure to fire," Journal of Constructional Steel Research, vol. 63, no. 8, pp. 1116-1126, 2007.

[15] M. C. Sundarraja, P. Sriram, and G. Ganesh Prabhu, "Strengthening of hollow square sections under compression using FRP composites," Advances in Materials Science and Engineering, vol. 2014, Article ID 396597, 19 pages, 2014.
[16] N. K. Photiou, L. C. Hollaway, and M. K. Chryssanthopoulos, "Strengthening of an artificially degraded steel beam utilising a carbon/glass composite system," Construction and Building Materials, vol. 20, no. 1-2, pp. 11-21, 2006.

[17] A. Parvin and D. Brighton, "FRP composites strengthening of concrete columns under various loading conditions," Polymers, vol. 6, no. 4, pp. 1040-1056, 2014. 

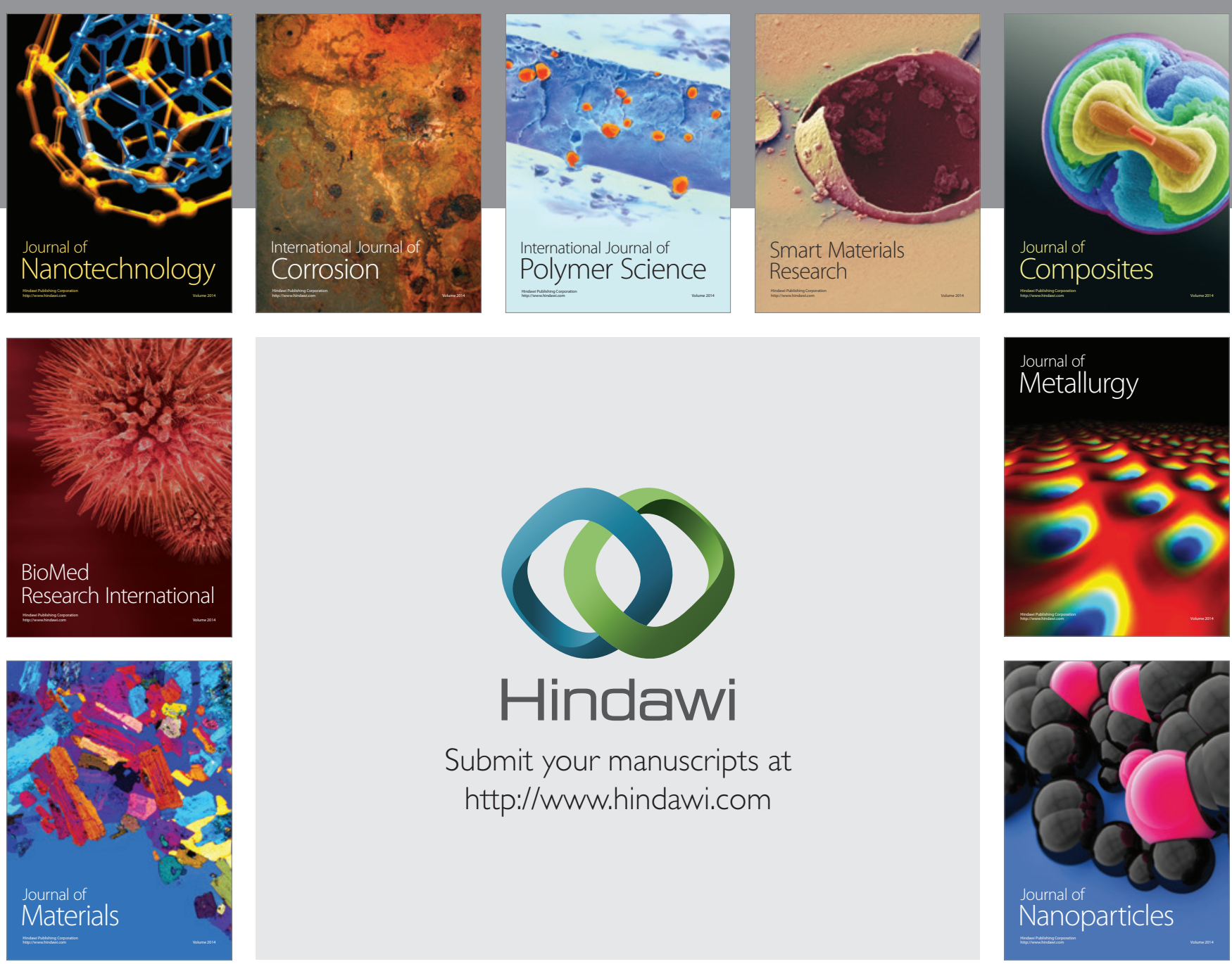

Submit your manuscripts at http://www.hindawi.com
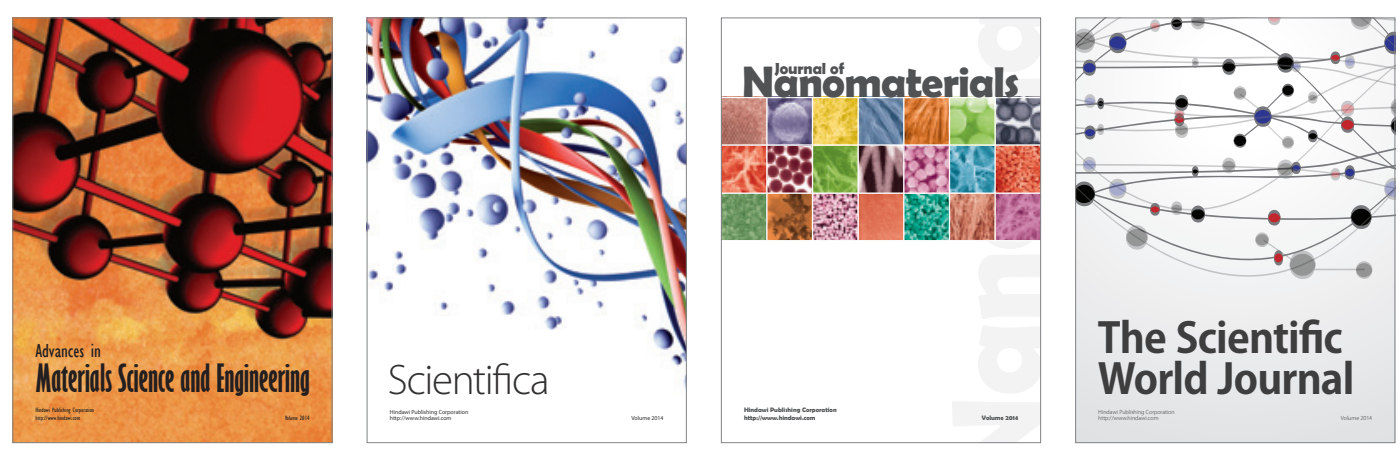

\section{The Scientific World Journal}
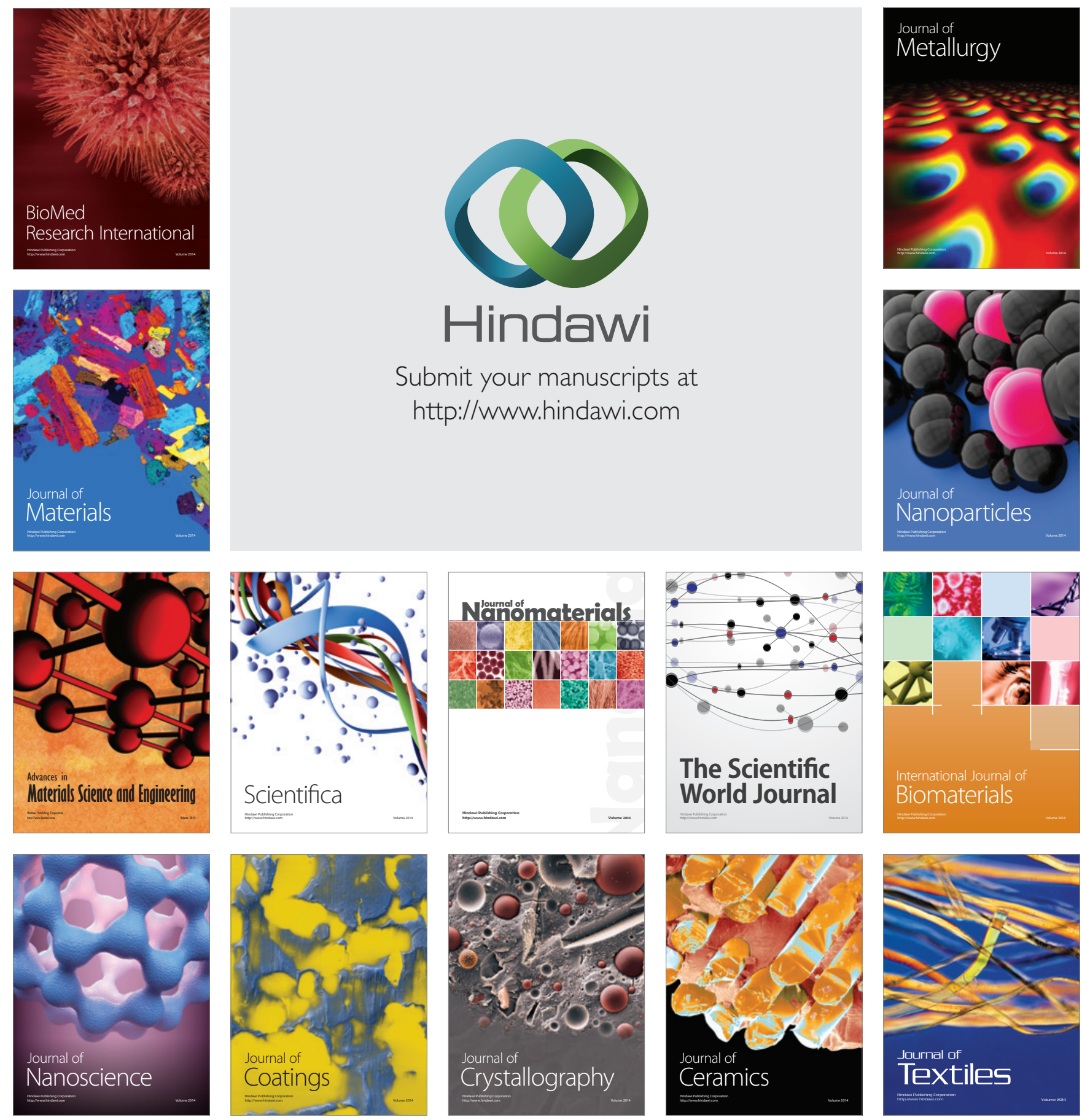